Part of Journal of Research of the National Bureau of Standards, Volume 30, May 1943

\title{
PERFORATED COVER PLATES FOR STEEL COLUMNS: COMPRESSIVE PROPERTIES OF PLATES HAVING A NET-TO-GROSS CROSS-SECTIONAL-AREA RATIO OF 0.33
}

\author{
By Ambrose H. Stang and Martin Greenspan
}

\section{ABSTRACT}

Tests were made to determine the mechanical properties of perforated cover plates intended to be used as a substitute for lattice bars or batten plates in builtup box-type columns. Each test column was built up from one perforated plate and four angles. Two columns had circular and two ovaloid perforations. For each column the ratio of net-to-gross cross-sectional area in the plate was 0.33 .

In this paper the methods of test are described, and the results of the tests of the four columns are given.

\section{CONTENTS}

Page

I. Introduction

II. Cover-plate columns

1. General

2. Dimensions

III. Procedure

1. Coupons _... 413

2. Columns $\ldots \ldots$

(a) Elastic range.......... 413

(b) Maximum load

IV. Results _...

1. Coupons

2. Columns _........... 415

(a) Modulus of column and effective area of plate...... 415

(b) Stresses........ 415

(1) On the edge of the perforation _........ 415

(2) On the surface of the plate...... 416

(c) Maximum load tests........ 416

(1) Stress-strain graphs

(2) Deflections

(3) Maximum loads

\section{INTRODUCTION}

This paper is the sixth of a series dealing with the mechanical properties of perforated cover plates intended to be used as a substitute for lattice bars or batten plates in built-up box-type columns. An outline of the program and results for plates having a net-to-gross cross-sectional-area ratio of 0.55 and having width-to-thickness ratios of 40,53 , and 68 have been given in previous Research Papers.'

1 imbrose H. Stang and Martin Greenspan, Perforated cover plates for steel columns: Program and test methods, J. Research NBS 28, 669 (1942) RP1473; Perforated cover plates for steel columns: Compressive properties of plates having ovaloid perforations and a width-to-thickness ratio of 40, 28, 687 (1942) RP1474; Perforated cover plates for steel columns: Compressive properties of plates having ovaloid perforations and a width-to-thickness ratio of 68, 29, 279 (1942) RP1501; Perforated cover plates for steel columns: Compressive properties of plates having ovaloid perforations and a width-to-thickness ratio of 53, 30, 15 (1943) RP1514; Perforated cover plates for steel columns: Compressive properties of plates having circular perforations and a width-to-thickness ratio of 53, 30,177 (1943) RP1527. 
In this paper are presented the test results for the $C 6$ and $C^{y}$ columns. The plates in these columns were 30 inches wide by $3 / 8$ in. thick, thus having a width-to-thickness ratio of 80 . The plates of the $C 6$ columns had circular perforations $10 \mathrm{in}$. in diameter and those of the $C 7$ columns ovaloid perforations $10 \mathrm{in}$. wide. The net-to-gross cross-sectional-area ratio was 0.33 .

The columns had been riveted and the column ends planed before delivery to the laboratory.

The dimensions and areas were determined, and the testing procedures and methods of calculation for the coupons and columns were made in the same manner as for the perforated-plate columns previously tested, ${ }^{2}$ except for those procedures which differed because the plates and angles of the columns had been riveted together or because columns without perforations had not been prepared.

\section{COVER-PLATE COLUMNS}

\section{GENERAL}

The details of the columns are shown in figure 1. There were two $C 6$ and two $C^{\prime y}$ columns. The cutting diagrams for the plate and angle material are also shown in figure 1. The plates for the four columns were all cut from the same length. The four angles for each column were all cut from the same length. The designations for the plates and angles, as indicated by the match marks in the cutting diagrams of figure 1 , for the columns are given in table 1 .

TABLE 1.-The plates and angles in the columns

\begin{tabular}{|r|r|c|}
\hline \hline $\begin{array}{c}\text { Column desig- } \\
\text { nation }\end{array}$ & $\begin{array}{c}\text { Plate desig- } \\
\text { nation }\end{array}$ & Angle designations \\
\cline { 1 - 3 } & $F(0-1)$ & $A(0-1), A(2-3), A(4-5), A(6-7)$ \\
$C 6 A$ & $F(2-3)$ & $B(0-1), B(2-3), B(4-5), B(6-7)$ \\
$C^{7} A A$ & $C(0-1), C(2-3), C(4-5), C(6-7)$ \\
$C^{7} B$ & $F(4-5)$ \\
& $F(6-7)$ & $D(0-1), D(2-3), D(4-5), D(6-7)$ \\
\hline
\end{tabular}

\section{DIMENSIONS}

The dimensions given in figure 1 are nominal. Direct measurements of the plates and angles could not be made, since they were riveted together. Measurements ${ }^{3}$ of the width and thickness were therefore made on the three separate pieces $2 \mathrm{ft}$ long submitted for coupons for each length. The gross cross-sectional area of each of the four main sections of each length was taken as the average of the cross-sectional areas of the three 2-ft lengths. The net width of the plate was taken as the gross width minus the average of the widths of all the perforations. The net area of the plate was taken as the product of the average thickness and the average net width.

2 See Research Paper RP1473.

3 See page 676 of RP1473. 

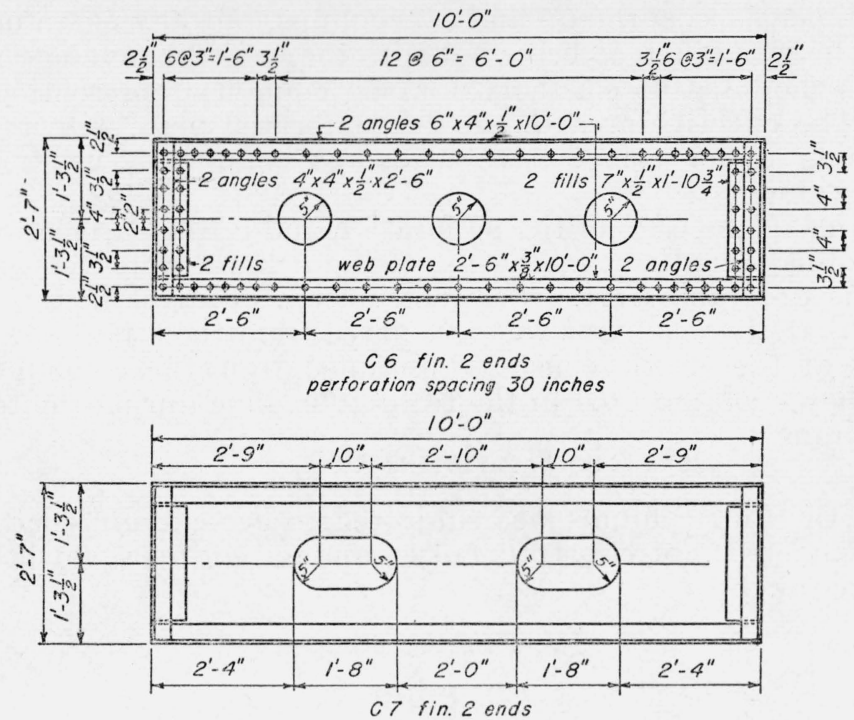

$C 7$ is a duplicate of $C 6$ except as shown perforation spacing 44 inches

\begin{tabular}{|c|c|c|c|c|c|c|}
\hline 0 & 1122 & & 3344 & & $56 \sqrt{6}$ & \\
\hline$c 6$ & & $C 6$ & & $c 7$ & & $c 7$ \\
\hline $10^{\prime}-0^{\prime \prime}$ & $2^{\prime}-\sigma^{\prime \prime}$ & $10^{\prime}-0^{\prime \prime}$ & $2^{\prime} 0_{1}^{\prime \prime}$ & $10^{\prime}-0^{\prime \prime}$ & $2-0_{1}^{\prime \prime}$ & $10^{\prime}-0^{\prime \prime}$ \\
\hline \multicolumn{7}{|c|}{ I plaie $2^{\prime}-6^{\prime \prime} \times \frac{3^{\prime \prime}}{8} \times 46^{\prime}-0^{\prime \prime}$} \\
\hline
\end{tabular}

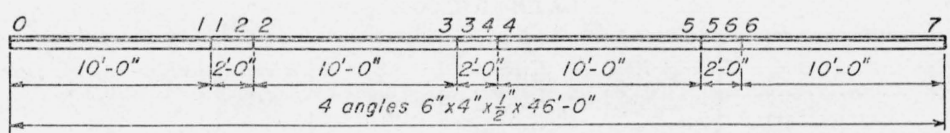

FIgURE 1.-Details of the $C 6$ and $C 7$ columns and cutting diagrams for the plate and angle material.

\section{PROCEDURE}

\section{COUPONS}

Coupons representing the plate and angle material were cut in the direction of rolling and tested in tension. Young's modulus of elasticity, E; Poisson's ratio, $\nu$; yield point; tensile strength; and elongation were determined.

A composite sample of the material from the $C 6$ and from the $C 7$ columns was analyzed for carbon, manganese, phosphorus, and sulfur.

\section{COLUMNS}

(a) ELASTIC RANGE

The shortening under load in the elastic range was determined for each column, and the modulus $E^{\prime}{ }_{p}$ was computed. Since columns similar to the $C 6$ and $C 7$ columns, but having an unperforated plate, were not available, the modulus $E^{\prime}{ }_{s}$ of hypothetical columns having 


\section{Journat of Research of the National Bureau of Standards}

the same dimensions as the $C 6$ and $C 7$ columns, but having an unperforated plate, was taken as being equal to the weighted average value of Young's modulus of elasticity for the coupons representing the column. The effective area, $K$, of the perforated plate with respect to shortening under compressive load was computed, using these $E_{p}^{\prime}$ and $E_{s}^{\prime}$ values. ${ }^{4}$

The strains in the edge of the perforation and in the surfaces of the plate in the bay-length at midheight of the column were determined for columns $C 6 A$ and $C^{\prime} 7 A$. The distribution of stress in this baylength for these two columns was calculated from the strain data and the values of the elastic constants obtained from the coupon tests. Figure 2 shows column $C 6 A$ in the testing machine during the test in the elastic range.

(b) MAXIMUM LOAD

Each of the four columns was subjected to a maximum-load test. Data to complete the stress-strain curves and data for stress-deflection curves were taken.

\section{RESULTS}

\section{COUPONS}

The results of the tensile tests of the coupons are given in table 2 .

TABLE 2.-Results of tensile tests of coupons

\begin{tabular}{|c|c|c|c|c|c|c|}
\hline Coupon designation & Thickness & $\begin{array}{c}\text { Young's } \\
\text { modulus of } \\
\text { elasticity, } \\
E\end{array}$ & $\begin{array}{l}\text { Poisson's } \\
\text { ratio, } \nu\end{array}$ & $\begin{array}{l}\text { Yield } \\
\text { point }\end{array}$ & $\begin{array}{l}\text { Tensile } \\
\text { strength }\end{array}$ & $\begin{array}{c}\text { Elongation } \\
\text { in } 8 \text { in. }\end{array}$ \\
\hline \multicolumn{7}{|c|}{ PLATE COUPONS } \\
\hline $\begin{array}{l}F(1-2) \\
F(3-4) \\
F(4-5)\end{array}$ & $\begin{array}{l}\text { Inch } \\
0.383 \\
.385 \\
.385\end{array}$ & $\begin{array}{c}\text { Kips/in. }{ }^{2} \\
29,500 \\
29.600 \\
29,600\end{array}$ & $\begin{array}{l}0.281 \\
.281 \\
.281\end{array}$ & $\begin{array}{r}\text { Kips/in. }{ }^{2} \\
37.5 \\
38.4 \\
37.9\end{array}$ & $\begin{array}{r}\text { Kips/in. }{ }^{2} \\
59.3 \\
59.1 \\
59.1\end{array}$ & $\begin{array}{r}\text { Percent } \\
33.0 \\
34.8 \\
33.0\end{array}$ \\
\hline
\end{tabular}

ANGLE COUPONS

\begin{tabular}{|c|c|c|c|c|c|c|}
\hline $\begin{array}{l}A(1-2) \\
A(3-4) \\
A(5-6) \\
B(1-2) \\
B(3-4) \\
B(5-6) \\
C(1-2) \\
C(3-4) \\
C(5-6) \\
D(1-2) \\
D(3-4) \\
D(5-6)\end{array}$ & $\begin{array}{l}0.507 \\
.511 \\
.503 \\
.508 \\
.499 \\
.513 \\
.501 \\
.510 \\
.505 \\
.500 \\
.497 \\
.501\end{array}$ & $\begin{array}{l}29,700 \\
29,500 \\
29,600 \\
29,600 \\
29,500 \\
29,500 \\
29,800 \\
29,900 \\
29,600 \\
29,700 \\
29,700 \\
29,700\end{array}$ & $\begin{array}{l}0.290 \\
.280 \\
.285 \\
.291 \\
.283 \\
.282 \\
.290 \\
.283 \\
.283 \\
.282 \\
.283 \\
.282\end{array}$ & $\begin{array}{l}35.7 \\
36.9 \\
35.8 \\
40.9 \\
40.6 \\
41.9 \\
36.6 \\
37.8 \\
37.4 \\
35.8 \\
36.6 \\
35.9\end{array}$ & $\begin{array}{l}61.9 \\
61.9 \\
61.2 \\
68.7 \\
69.3 \\
68.7 \\
64.0 \\
63.8 \\
64.0 \\
59.2 \\
59.4 \\
59.3\end{array}$ & $\begin{array}{l}32.0 \\
33.9 \\
32.9 \\
30.9 \\
26.3 \\
31.0 \\
28.7 \\
31.5 \\
29.9 \\
31.8 \\
32.2 \\
34.2\end{array}$ \\
\hline
\end{tabular}

The chemical composition of the coupon material is given below.

\begin{tabular}{|c|c|c|c|c|}
\hline Composite sample & Carbon & $\begin{array}{c}\text { Manga- } \\
\text { nese }\end{array}$ & $\begin{array}{l}\text { Phos- } \\
\text { phorus }\end{array}$ & Sulfur \\
\hline $\begin{array}{l}\text { Columns } C^{6} \\
\text { Columns } C^{7}\end{array}$ & $\begin{array}{r}\text { Percent } \\
0.17 \\
.22\end{array}$ & $\begin{array}{r}\text { Percent } \\
0.59 \\
.71\end{array}$ & $\begin{array}{r}\text { Percent } \\
0.007 \\
.017\end{array}$ & $\begin{array}{r}\text { Percent } \\
0.033 \\
.033\end{array}$ \\
\hline
\end{tabular}

\footnotetext{
. ${ }^{4}$ See page 680 of RP1473.
} 


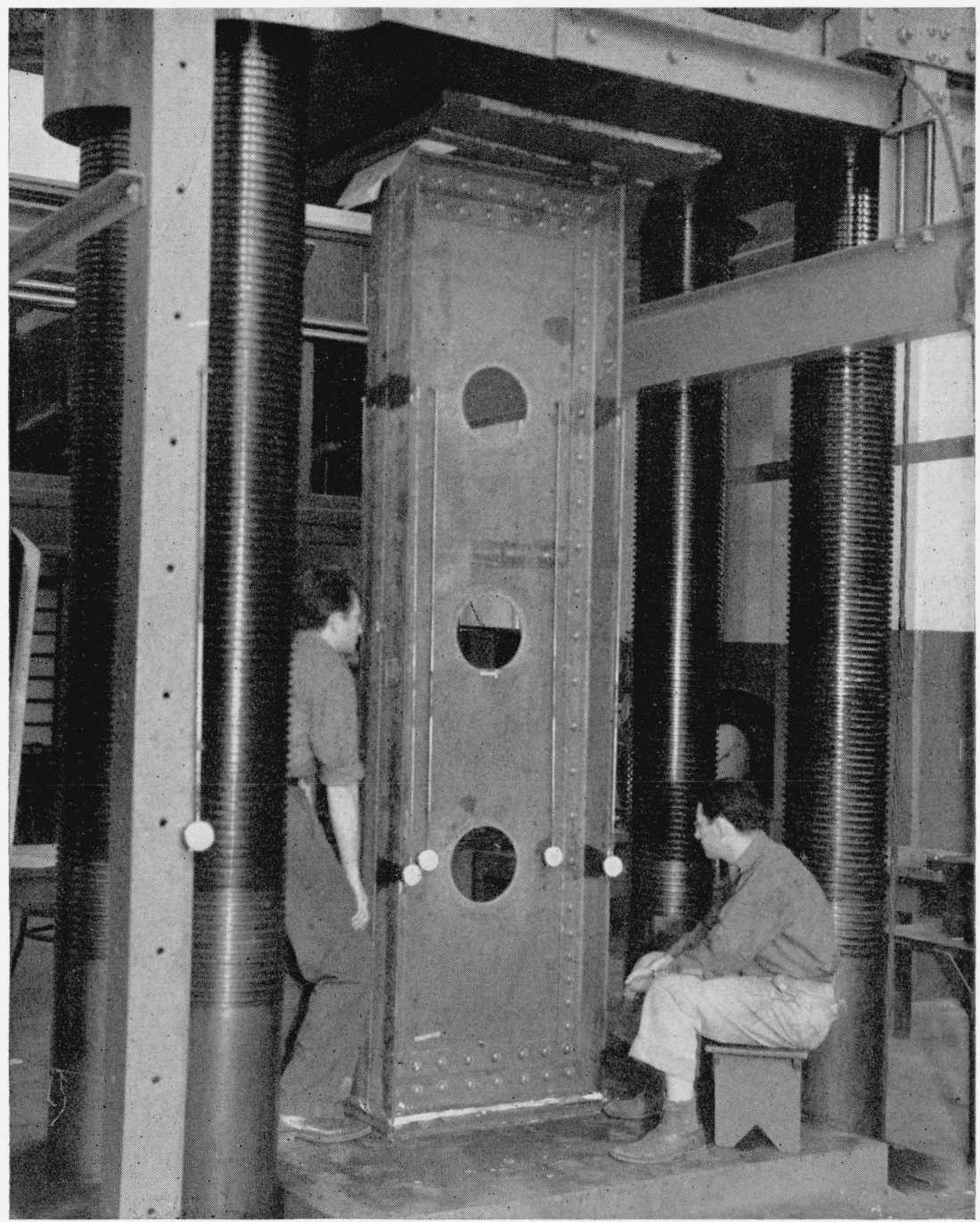

Figure 2.-Column C6A in the testing machine during the test in elastic range. 


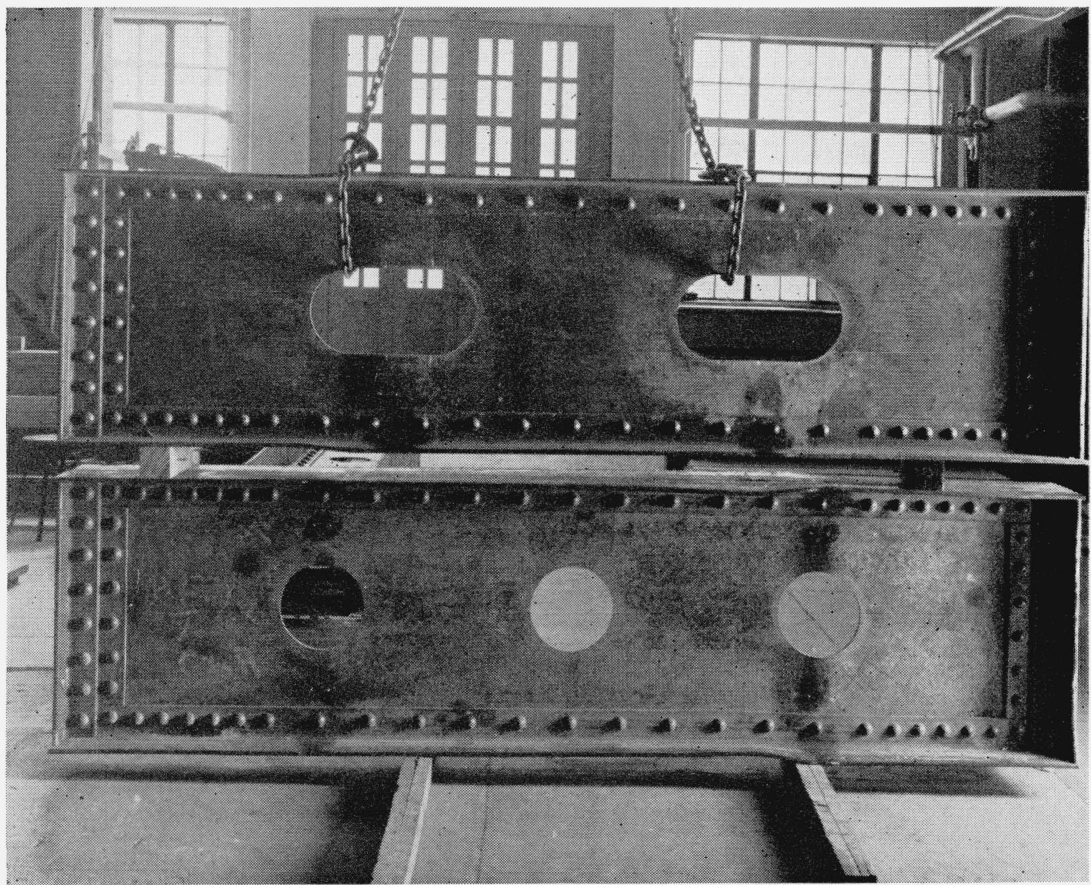

Figure 15.-Columns $C 6 A$ and $C 7 B$ after the maximum load test. Column $C 6 A$ below Column $C 7 B$. 


\section{COLUMNS}

(a) MODULUS OF COLUMN AND EFFECTIVE AREA OF PLATE

The moduli, $E_{s}^{\prime}$, of hypothetical unperforated plate columns, moduli, $E_{p}^{\prime}$, of the tested columns, and effective-area factors, $K$, with respect to shortening under compressive load, for the plates, are given in table 3.

TABLE 3.- Moduli of columns, effective-area factors of plates and maximum stress ratios

\begin{tabular}{|c|c|c|c|c|c|c|}
\hline Column ... & $C 6 A$ & $C 6 B$ & C6 avg. & $C 7 A$ & $C 7 B$ & $C 7$ avg. \\
\hline Unperforated-plate column modulus, $E_{\mathrm{s}}^{\prime}$, kips/in.2 ${ }^{2}$ & 29,600 & 29,600 & 29,600 & 29,700 & 29,600 & 29,700 \\
\hline
\end{tabular}

VALUES BASED ON GROSS CROSS-SECTIONAL AREA

\begin{tabular}{l|r|r|r|r|r}
\hline Modulus, $E_{p}^{\prime}$, kips/in.2 & 27,300 & 26,900 & 27,100 & 26,900 & 26,400 \\
Effective-area factor, $K$ \\
Ratio, maximum stress $\frac{26,600}{P / A}$
\end{tabular}

VALUES BASED ON NET CROSS-SECTIONAL AREA

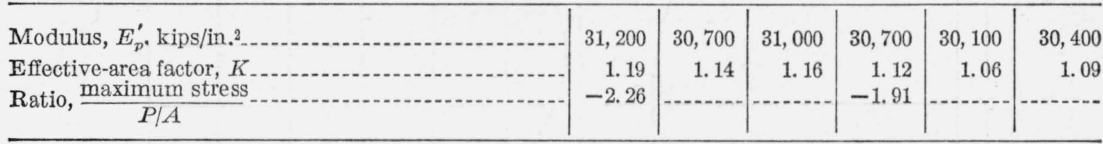

(b) STRESSES

(1) On the Edge of the Perforation.-The distribution of stress on the edge of the perforation near midheight of the columns is indicated in figures 3 and 4 . The vertical axis of the graph in each figure is a development of one quadrant of the dege of the perforation.

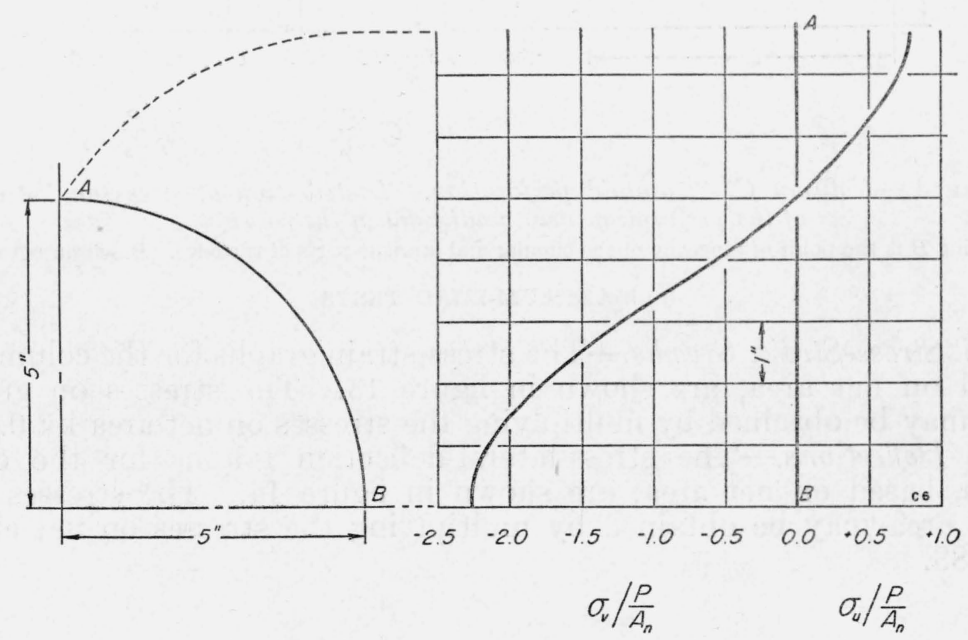

Figure 3.-Column C6A, circular perforation. Distribution of stress on the edge of the middle perforation.

Based on net area. 
In the stress ratios $\sigma_{u, v} /\left(P / A_{n}\right), A_{n}$ is the net cross-sectional area of the column, and $\sigma_{u}$ and $\sigma_{v}$ are the maximum and the minimum principal stresses, respectively. The stress ratios based on gross area, $\sigma_{u, v} /(P / A)$, may be obtained by multiplying $\sigma_{u, v} /\left(P / A_{n}\right)$ by 1.14 for either column.

The maximum stress ratios are given in table 3.

(2) On the Surfaces of the Plate.- The distributions of stress on the surfaces of the plate near midlength of the columns are indicated in figures 5 to 12 , inclusive. The stress ratios shown in these figures are based on net area. The stress ratios based on gross area may be obtained by multiplying the given values by 1.14 .

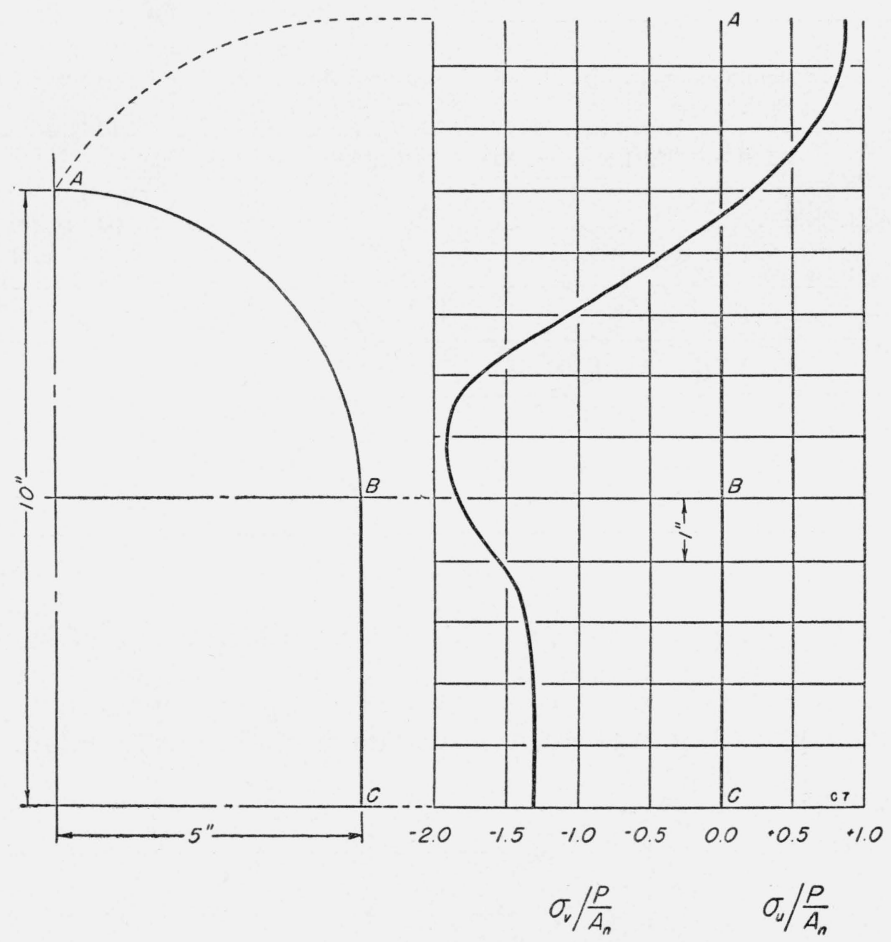

Figure 4.-Column CrA, ovaloid perforation. Distribution of stress on the edge of the perforation near midheight of the column.

The point $B$ is the point of tangency of the circular and straight parts of the edge. Based on net area.

\section{(c) MAXIMUM-LOAD TESTS}

(1) Stress-Strain Graphs.-The stress-strain graphs for the columns, based on net area, are shown in figure 13. The stresses on gross area may be obtained by multiplying the stresses on net area by 0.88 .

(2) Deflections.- The stress-lateral-deflection graphs for the columns, based on net area, are shown in figure 14. The stresses on gross area may be obtained by multiplying the stresses on net area by 0.88 . 


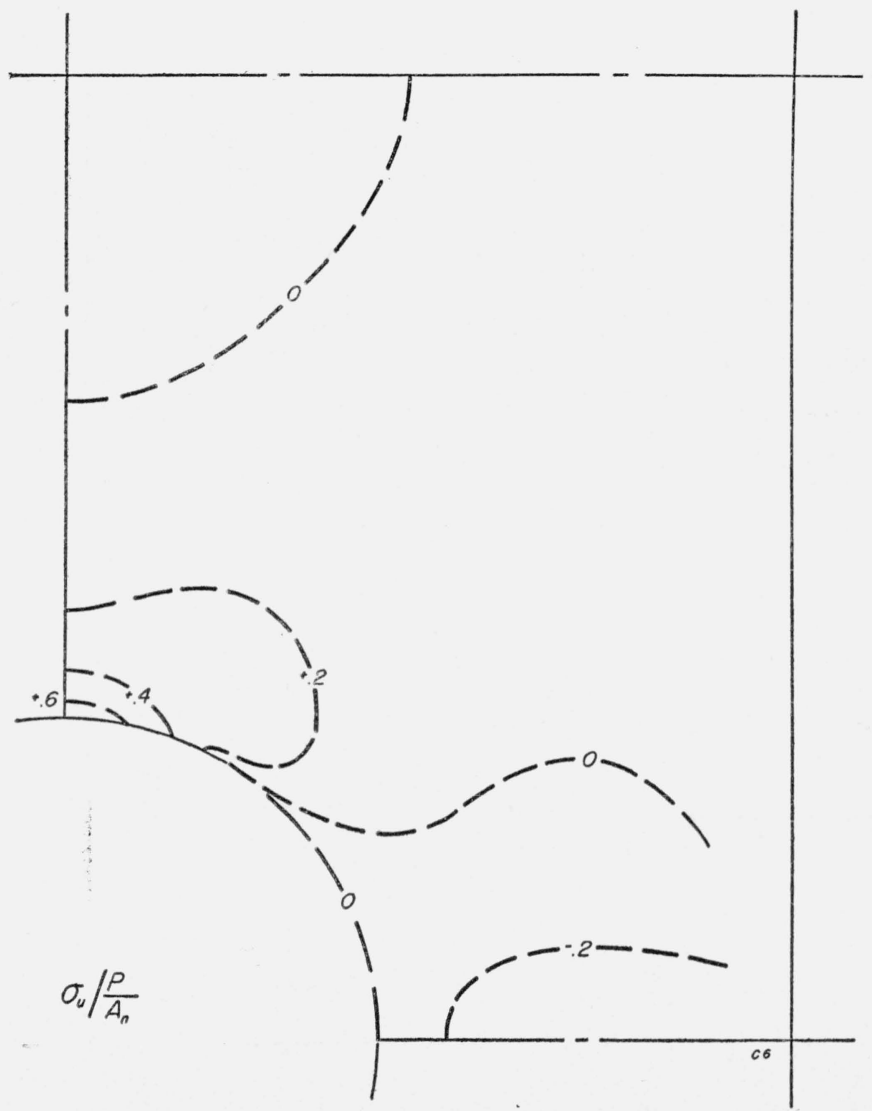

Figure 5.-Column C6A, circular perforation. Isogram of maximum principal stress.

Based on net area. 
418 Journal of Research of the National Bureau of Standards

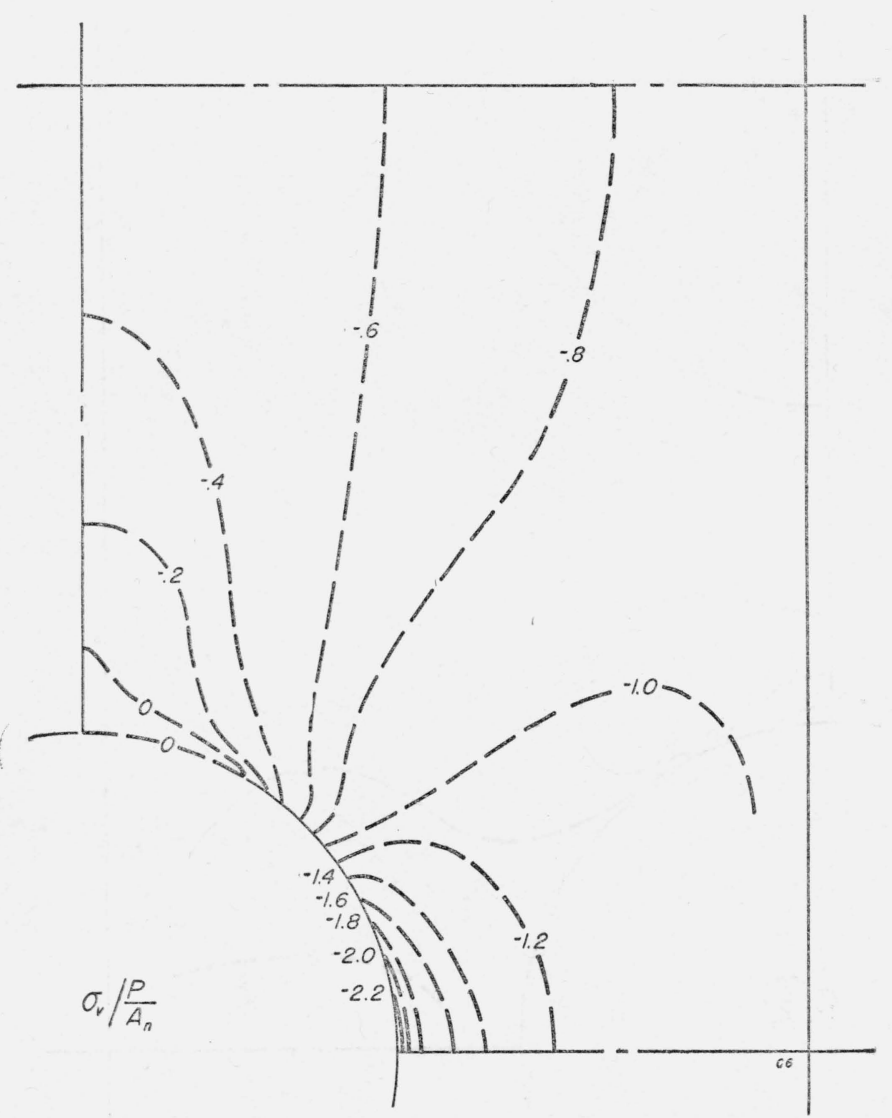

Figure 6.-Column C6A, circular perforation. Isogram of minimum principal stress.

Based on net area. 


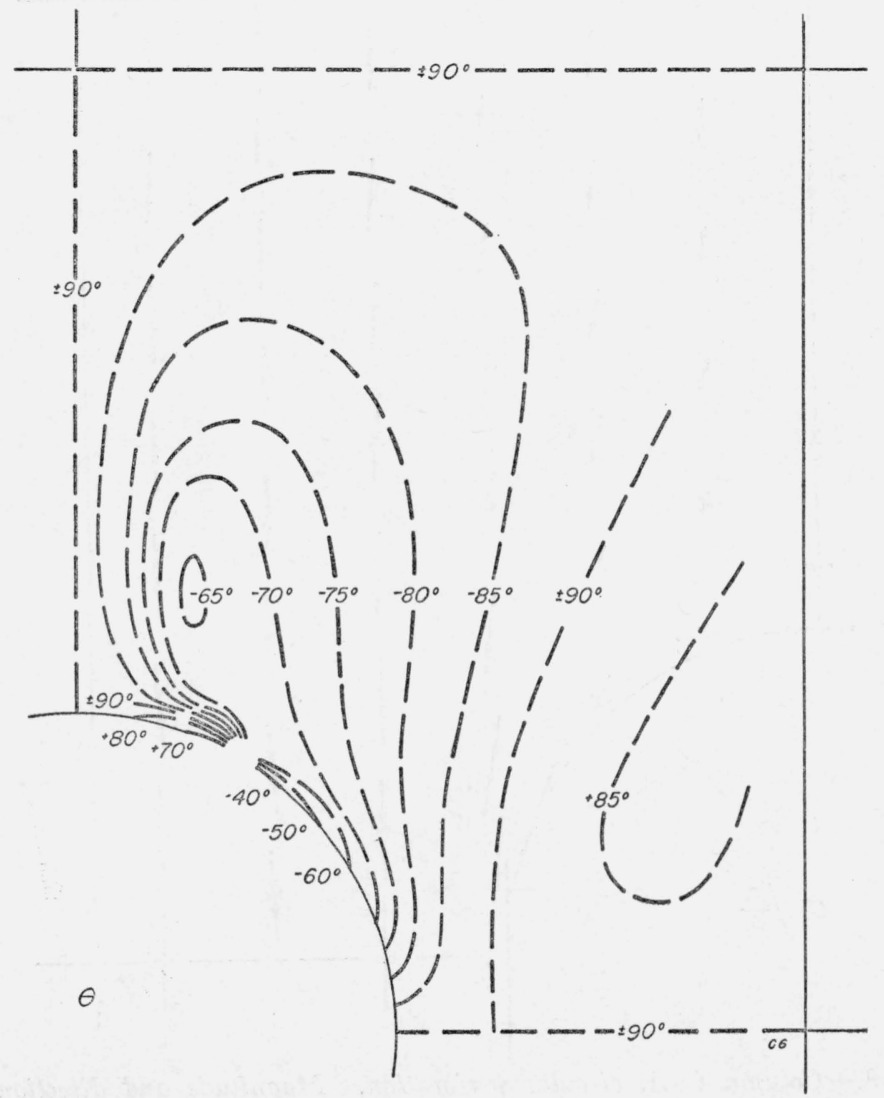

Figure 7.-Column C6A, circular perforation. Isoclinics.

The angle $\theta$ is measured positive counterclockwise from the axis of the column to the direction of the maximum principal stress. 
420 Journal of Research of the National Bureau of Standards

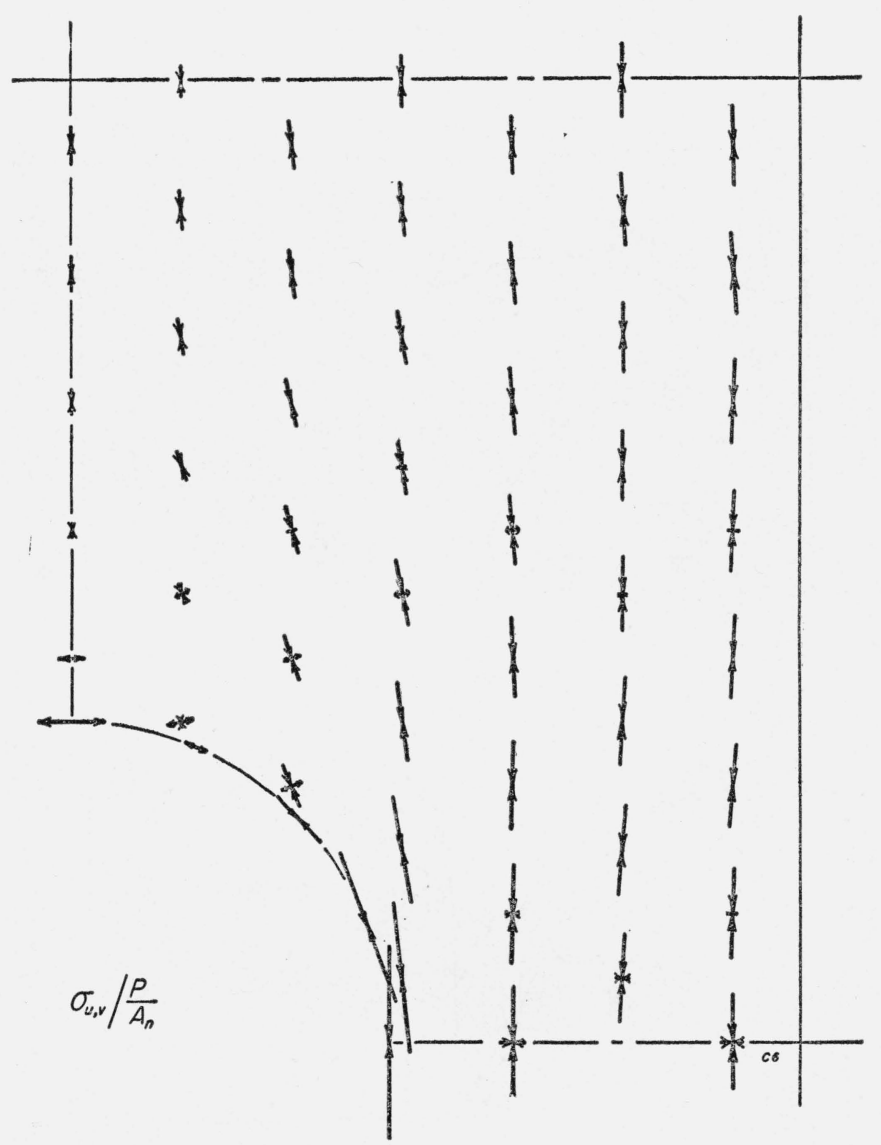

FIgure 8.-Column C6A, circular perforation. Magnitude and direction of the principal stresses.

Based on net area. 


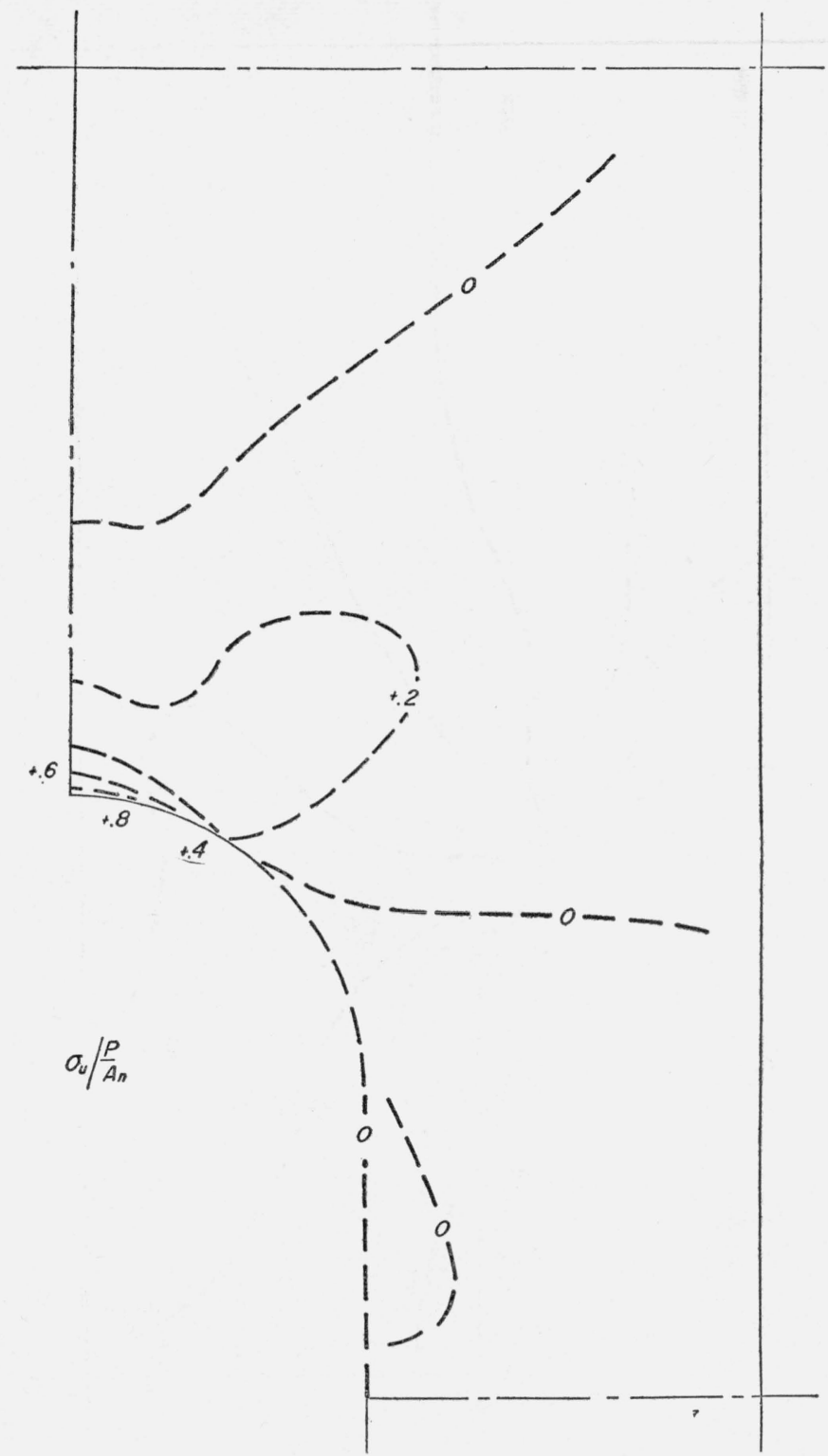

FIGURE 9.-Column C7A, ovaloid perforation. Isogram of maximum principal stress.

Based on net area. 


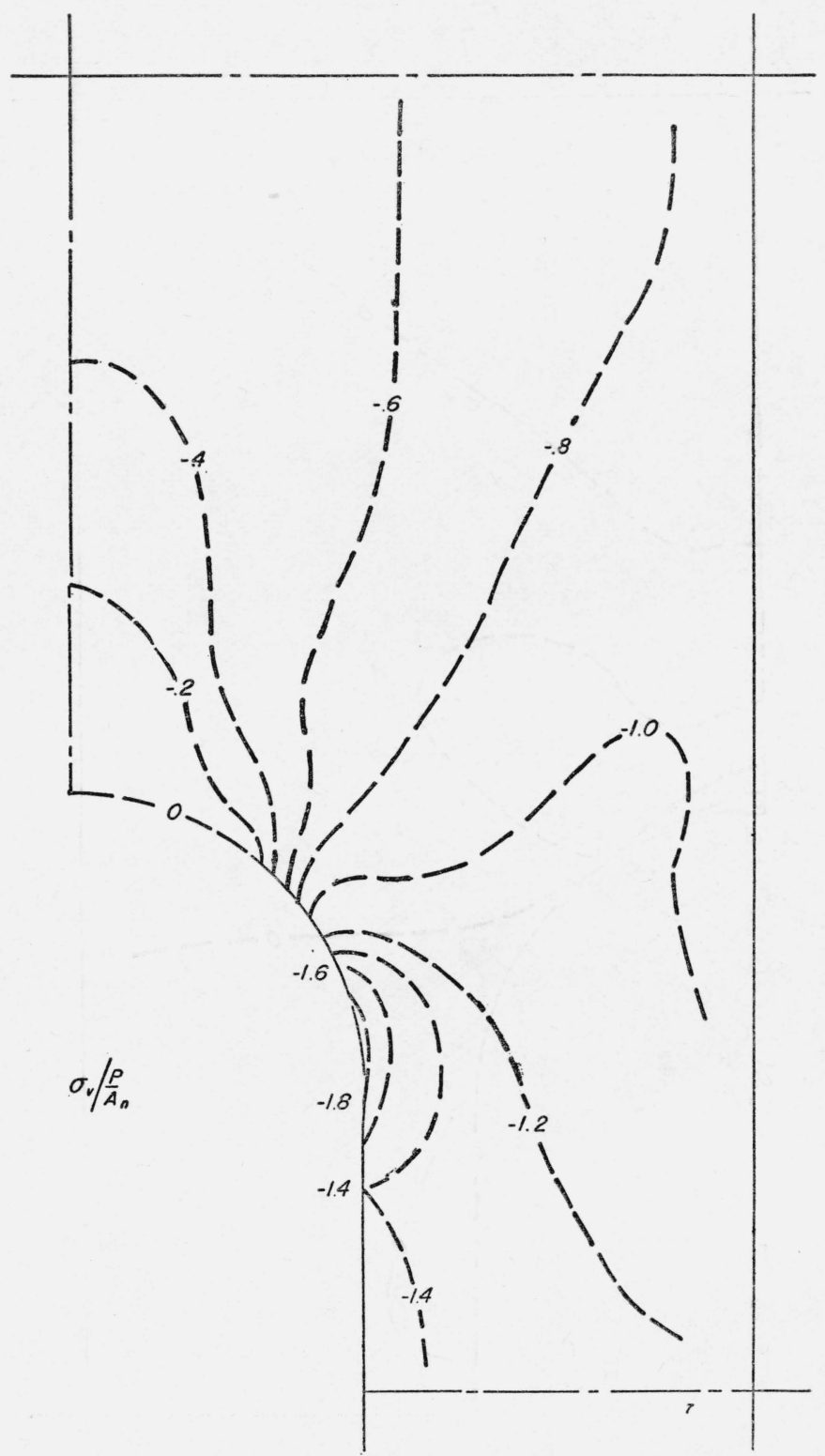

FIgURe 10.-Column $C 7 A$, ovaloid perforation. Isogram of minimum principal stress.

Based on net area. 


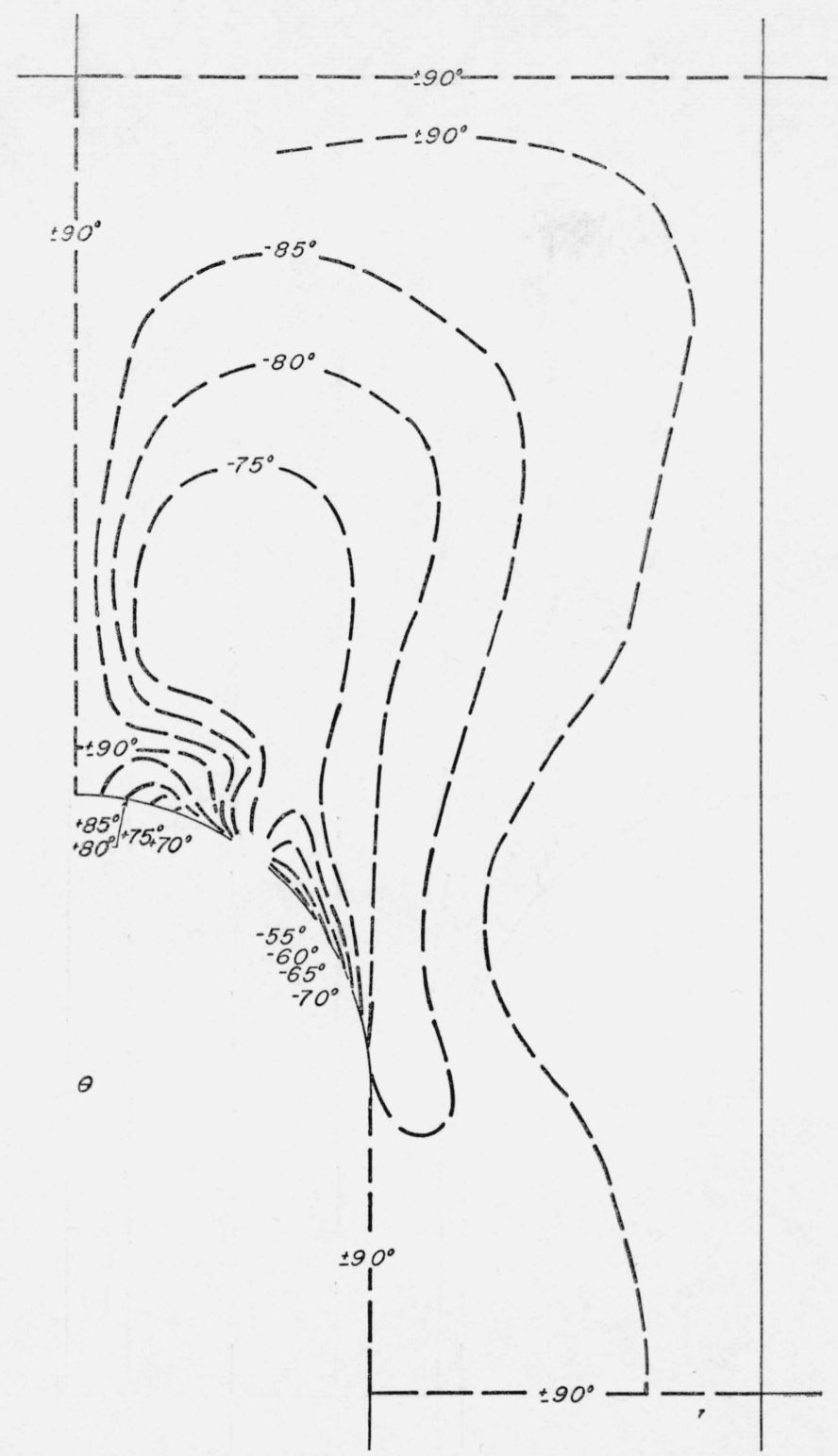

FiguRE 11.-Column C7y ovaloid perforation. Isoclinics.

The angle $\theta$ is measured positive counterclockwise from the axis of the column to the direction of the maximum principal stress. 
424 Journal of Research of the National Bureau of Standards

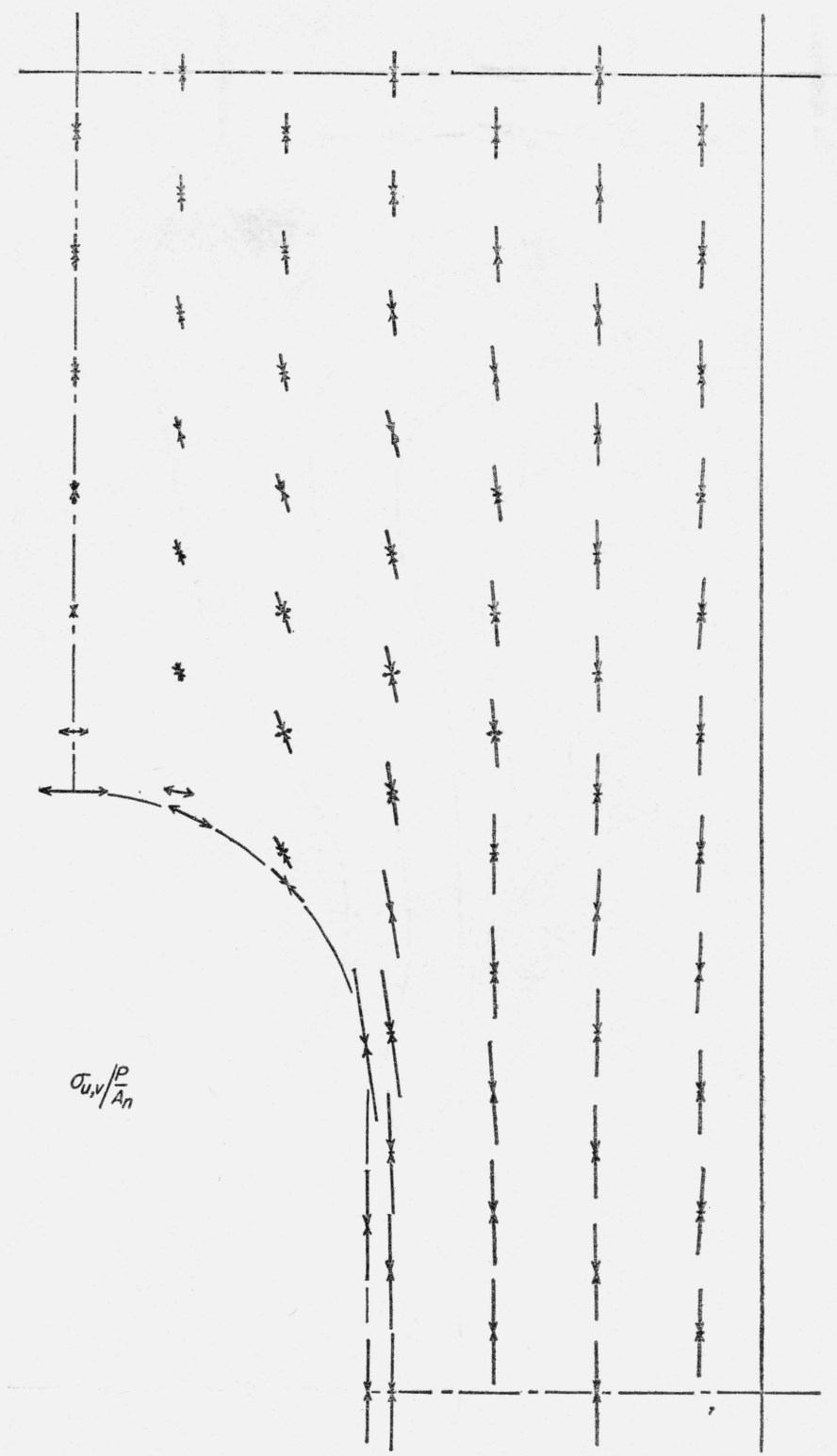

FIgure 12.-Column CrA, ovaloid perforation. Magnitude and direction of the principal stresses.

Based on net area. 


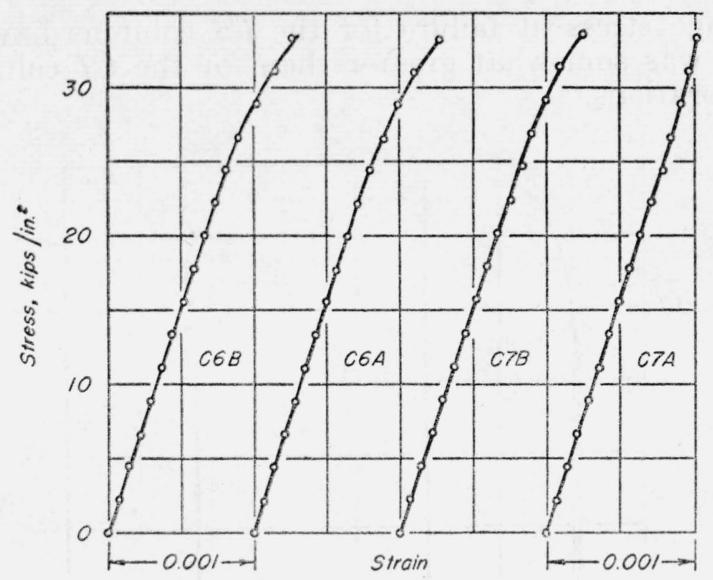

Figure 13.-Columns $C 6$ and C7. Stress-strain graphs.

Based on net area.

(3) Maximum Loads.-The maximum loads for the columns and the maximum average stress on the gross area and on the net area are given in table 4 .

TABLE 4.-Maximum loads for columns

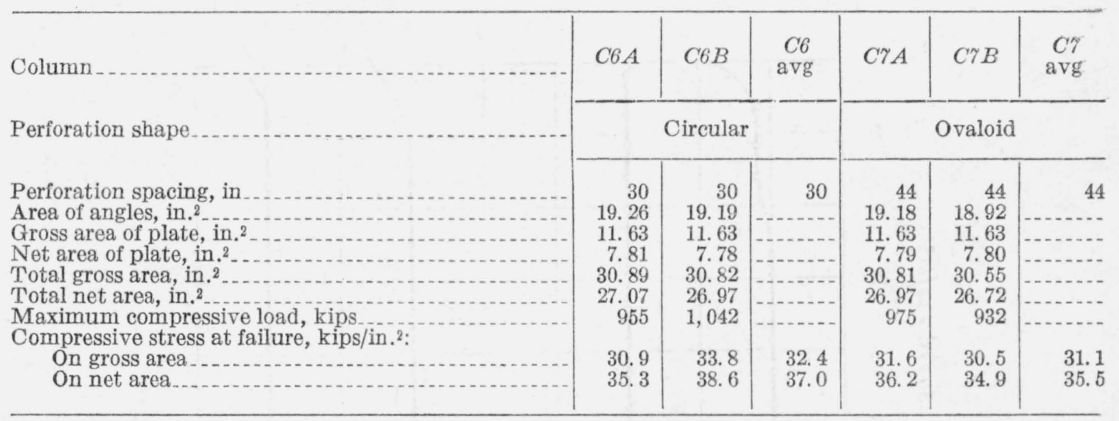

The effective-area factors of the plates with respect to compressive stress could not be determined, because no columns with unperforated plates were furnished.

The columns all failed by buckling of the plates near one of the perforations, as may be noted in figure 15. After the maximum load had been reached, secondary buckling occurred in the outstanding legs of the angles near the buckles in the plate. 
The average stress at failure for the $C 6$ columns having circular perforations was somewhat greater than for the $C^{\prime 7}$ columns having ovaloid perforations.
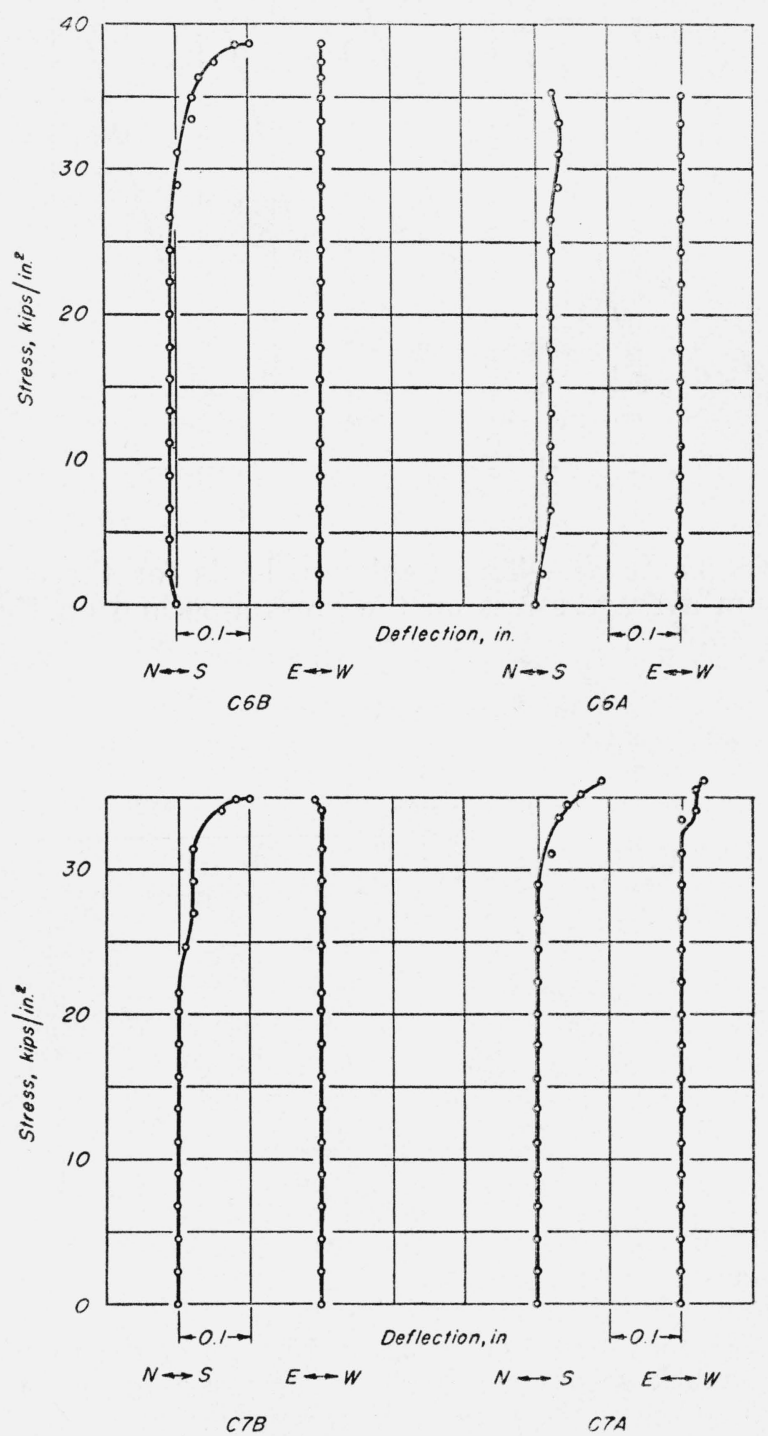

Figure 14.-Columns $C 6$ and C7. Stress-deflection graphs. Based on net area.

Washington, February 6, 1943. 


\section{MATHEMATICAL TABLES}

Attention is invited to a series of publications which is being prepared by the Project for the Computation of Mathematical Tables conducted by the Federal Works Agency, Work Projects Administration for the City of New York under the sponsorship of the National Bureau of Standards. The tables which have been made available through the National Bureau of Standards are listed below.

There is included in this list a publication on the hypergeometric and Legendre functions (MT15), prepared by the Bureau.

MT1. Table or the Frrst Ten Powers of the Integers From 1 to 1000:

(1938) VIII+80 pages; heavy paper cover. 50 cents.

MT2. Tables of the Exponential Function $e^{x}$.

The ranges and intervals of the argument and the number of decimal places in the entries are given below:

$\begin{array}{ccc}\text { Range of } x & \text { Interval of } x & \text { Decimal given } \\ -2.5000 \text { to } 1.0000 & 0.0001 & 18 \\ 1.0000 \text { to } 2.5000 & .0001 & 15 \\ 2.500 \text { to } 5.000 & .001 & 15 \\ 5.00 \text { to } 10.00 & .01 & 12\end{array}$

(1939) XV + 535 pages; bound in buckram, $\$ 2.00$.

MT3. Tables of Circular and Hyperbolic Sines and Cosings for Radian Arguments:

Contains 9 decimal place values of $\sin x, \cos x, \sinh x$ and $\cosh x$ for $x$ (in radians) ranging from 0 to 2 at intervals of 0.0001 .

(1939) XVII + 405 pages; bound in buckram, $\$ 2.00$.

MT4. Tables of Sines and Cosines for Radian Arguments:

Contains 8 decimal place values of sines and cosines for radian arguments ranging from 0 to 25 at intervals of 0.001 .

(1940) XXIX + 275 pages; bound in buckram, $\$ 2.00$.

MT5. Tables of Sine, Cosine, and Exponential Intrgrals, Volume I:

Values of these functions to 9 places of decimals from 0 to 2 at intervals of 0.0001 .

(1940) XXVI+444 pages; bound in buckram, $\$ 2.00$.

MT6. Tables of Sine, Cosine, and Exponential Intggrals, Volume II:

Values of these functions to 9,10 , or 11 significant figures from 0 to 10 at intervals of 0.001 with auxiliary tables.

(1940) XXXVII + 225 pages; bound in buckram, $\$ 2.00$.

MT7. Table of Natural Logarithms, Volume I:

Logarithms of the integers from 1 to 50,000 to 16 places of decimals.

(1941) XVIII + 501 pages; bound in buckram, $\$ 2.00$.

mT8. Tables or Probability Functions, Volume I:

Values of these functions to 15 places of decimals from 0 to 1 at intervals of 0.0001 and from 1 to 5.6 at intervals of 0.001 .

(1941) XXVIII + 302 pages; bound in buckram, $\$ 2.00$.

[Continued on p. 4 of cover] 
MT9. Table or Natural Logarithm, Volume II:

Logarithms of the integers from 50,000 to 100,000 to 16 places of decimals.

(1941) XVIII + 501 pages; bound in buckram, $\$ 2.00$.

MT10. Table of Natural Logarithm, Volume III:

Logarithms of the decimal numbers from 0.0001 to 5.0000 , to 16 places of decimals. (1941) XVIII + 501 pages; bound in buckram, $\$ 2.00$.

MT11. Tables of the Moments of Inertia and Section Moduli of Ordinary Angles, Chan. nels, and Bulb Angles with Certain Plate Combinations:

(1941) XIII+197 pages; bound in green cloth. $\$ 2.00$.

MT12. Table or Natural Logarithms, Volumb IV:

Logarithms of the decimal numbers from 5.0000 to 10.0000 , to 16 places of decimals. (1941) XXII + 506 pages; bound in buckram, $\$ 2.00$.

MT13. Table of Sine and Cosine Intrgrals for Argumbnts From 10 to 100:

(1942) XXXII+185 pages, bound in buckram, $\$ 2.00$.

MT14. Tables or Probability Functions, Volume II:

Values of these functions to 15 places of decimals from 0 to 1 at intervals of 0.0001 and from 1 to 7.8 at intervals of 0.001 .

(1942) XXI + 344 pages; bound in buckram, $\$ 2.00$.

MT15. The hypergeometric and Legendre functions with applications to integral equations of potential theory. By Chester Snow, National Bureau of Standards. Reproduced from original handwritten manuscript.

(1942) VII + 319 pages; bound in heavy paper cover. $\$ 2.00$.

MT16. Table or Arc Tan X:

Table of inverse tangents for positive values of the angle in radians. Second central differences are included for all entries.

$\begin{array}{rrc}\text { Range of } x & \begin{array}{c}\text { Interval between } \\ \text { successive arguments }\end{array} \\ 0 \text { to } & 7 & 0.001 \\ 7 \text { to } 50 & .01 \\ 50 \text { to } 300 & .1 \\ 300 \text { to } 2,000 & 1 \\ 2,000 \text { to } 10,000 & 10\end{array}$

(1942) XXV+169 pages; bound in buckram, $\$ 2.00$.

Payment is required in advance. Make remittance payable to the "National Bureau of Standards," and send with order, using the blank form facing page 3 of the cover.

The prices are for delivery in the United States and its possessions and in countries extending the franking privilege. To other countries the price of MT1 is 65 cents; that of MT2 to MT16, inclusive, is $\$ 2.50$ each; remittance to be made payable in United States currency.

Copies of these publications have been sent to various Government depositories throughout the country, such as public libraries in large cities, and colleges and universities, where they may be consulted.

A mailing list is maintained for those who desire to receive announcements regarding new tables as they become available. 